\title{
Is bone kinesthetic adaptation of bone innervation plastically developed in fingers and correlated joints of violist and pianist after long term practice?
}

\author{
${ }^{1,2}$ Huibing Tan*, ${ }^{2,3}$ Yinhua Li, ${ }^{4,5}$ Hangqi Liu, ${ }^{4}$ Siyu Tian, ${ }^{1,6}$ Torin Chiles, ${ }^{2}$ Yunge Jia, ${ }^{2}$ Wei Hou, \\ ${ }^{2}$ Tianyi Zhang \\ ${ }^{1}$ New St. James Presbyterian Church, London, Ontario, Canada; ${ }^{2}$ Department of Anatomy, \\ Jinzhou Medical University, Jinzhou, China; ${ }^{3}$ Shanghai University of Sport, Shanghai, China; \\ ${ }^{4}$ Hainan maternal and Children's Medical Center, Hainan, China; ${ }^{5}$ College of Humanities and \\ management, Jinzhou Medical University; ${ }^{6}$ Don Wright Faculty of Music, Western University, \\ London, Ontario, Canada.
}

\begin{abstract}
Bone cells might be considered in response to the distribution of nerves in the periosteum, epiphysis and bone marrow.The sensory and sympathetic neurotransmitters have trophic effects critically on normal osteogenic differentiation and bone metabolism in bone development and regeneration. It could modulate bone regeneration, bone remodeling, and articular cartilage homeostasis to their classic neurological actions. With touching and hearing mediated osseoperception, sensation can be adapted from the mechanical stimulation of a bone-anchored prosthesis. Investigations of the influence of music on the human brain showed structural and functional cerebro-neuroplasticity emerge as a result of long-term musical practice, which may cause cognitive differences between non-musicians and musicians. Meanwhile, the physical mechanical hits and touch strings and keys of instruments hypothetically were considered to cause adaptability for professional musicians in their peripheral tissues, especially bone sensation of fingers and correlated joints. Music practice is bone-strengthening activity. We hypothesis that it produces sensation adaptation in the fingers and correlated joints of instrument players, especially musicians after tremendous training and practice. Both the bone, correlated joint and its innervation are adapted by neuroplasticity for something part of "hardware constructing" to accomplish music performance. We thought that neuroplasticity occurred both in central nervous system and peripheral nervous system. Besides of developed in soft tissues of subcutaneous, connective tissue, muscle, inter-tissue coordination through neuro-network may occur in bone innervation coupled with correlated joint for specialized music-practice-oriented neuroplasticity. Soft tissues, such as muscle and tendon cannot directly hit instrument with stiffness to generate sound and rhythmic. Functionally, innervated-bone as bio-mechanical device becomes sensory musical target bone.
\end{abstract}

Key words: bone innervation, music-practice-oriented neuroplasticity, musician, adaptation, bone sensory innervation

* Corresponding author: Huibing Tan. E-mail: davidtanhb@ foxmail.com 
Skeleton is a fundamental structure that makes body movement reliable from the order of the central nervous system (CNS). The bone is a targeting tissue of the nervous system (Bjurholm 1991, Hill and Elde 1991, García-Castellano, Díaz-Herrera et al. 2000, Ivanusic 2007). Bones are innervated not only sensory(Cao, Zhang et al. 2019) and sympathetic but also parasympathetic nerve fibers (Bajayo, Bar et al. 2012, Milovanovic and ! uri 2018). Bone cells might be considered in response to the distribution of nerves in the periosteum (Hill and Elde 1991), epiphysis (Edoff, Grenegård et al. 2000) and bone marrow (Calvo 1968). Bone nerves play an important role in skeletal development, adaptation, and aging (Elefteriou 2008, Tomlinson, Christiansen et al. 2020). Patients may feel pain for the sensory innervation of bones with bone diseases (Steverink, Oostinga et al. 2021).

The performing sensation and music perception of sensory-motor control may commonly consider muscles and ligaments /tendons. Finger position and pressure sensing is a very basic sensation for musical instrument players to control finger motion, gesture and forces while musician playing the musical instruments, especially strings and keyboards. For pianist, biomechanical and neuromuscular adaptations functionally improve dexterous control of both the individuated and coordinated finger movements(Kimoto, Hirano et al. 2021). As mentioned "asymmetry and imbalance in the muscular-skeletal system, muscle-bone-joint interactions, repetitive overloading and fatigue" by Mizrahi (Mizrahi 2020), we focus to discuss possibility of bone adaptation with innervation to subserve musical instrument performance. Formability of bone innervation also functions to healthily maintain neuronal-musculoskeletal system and innervation of bone and correlated joints.

Overuse syndrome is an "occupational injuries suffered by classical musicians"(Heming 2004). Heming summarizes definitions of overuse syndrome from several articles (Fry 1986, Fry 1989, Lockwood 1989, Hackney 1994, Byl, Merzenich et al. 1996, Sheon 1997). The concluded overuse syndrome is: "A clinical entity in its own right, caused by overload or repetition of some movements giving episodes of micro-trauma to muscle and joint ligaments, resulting in chronic inflammation and fibrosis as connective tissue is slowly taken beyond its biomechanical and physiological limits". We consider that skeleton is also involved in overuse syndrome, e.g. muscle, joint ligaments, skeleton and even skin as well as correlated connective tissue work as whole unite, like three in one or four in one compartment. Hackney's papers Heming cited demonstrate that "Overuse injuries are caused by repeated episodes of microtrauma that individually are insufficient to give rise to macroscopic injury. When healing mechanisms are overcome, however, the end result can be as serious as a fractured neck of femur from a completed stress fracture". Similarly, Zaza have mentioned that the similar problem can be "playing-related musculoskeletal disorders in classical musicians"(Zaza 1998). From perspective of finger representative region in cortex (increased cortical Representation of the fingers of the left Hand in string players)(Elbert, Pantev et al. 1995), we cannot neglect bones of fingers for musicians.

Before we start to demonstrate our hypothesis. We present a non-scientific illustration and a hi-tech bionic project as metaphor. Two hundred years ago, artists can imagine skeleton to perform musical performance (Figure 1). Figure 1 may show absurd in scientific view. And the second one shows reasonable in technology. Human hands show dexterity and adaptability. In order to develop a robotic device of manipulators comparable to human hands, researchers try to use an anthropomorphic 
skeleton hand to exploit conditional models to play piano(Hughes, Maiolino et al. 2018). Next, we will demonstrate that the bone is not bare structure, which is innervated with nerve. One of the physical property of the bone is stiffness. To accomplish a music making of instrument, the CNS requires feedback information from bone.

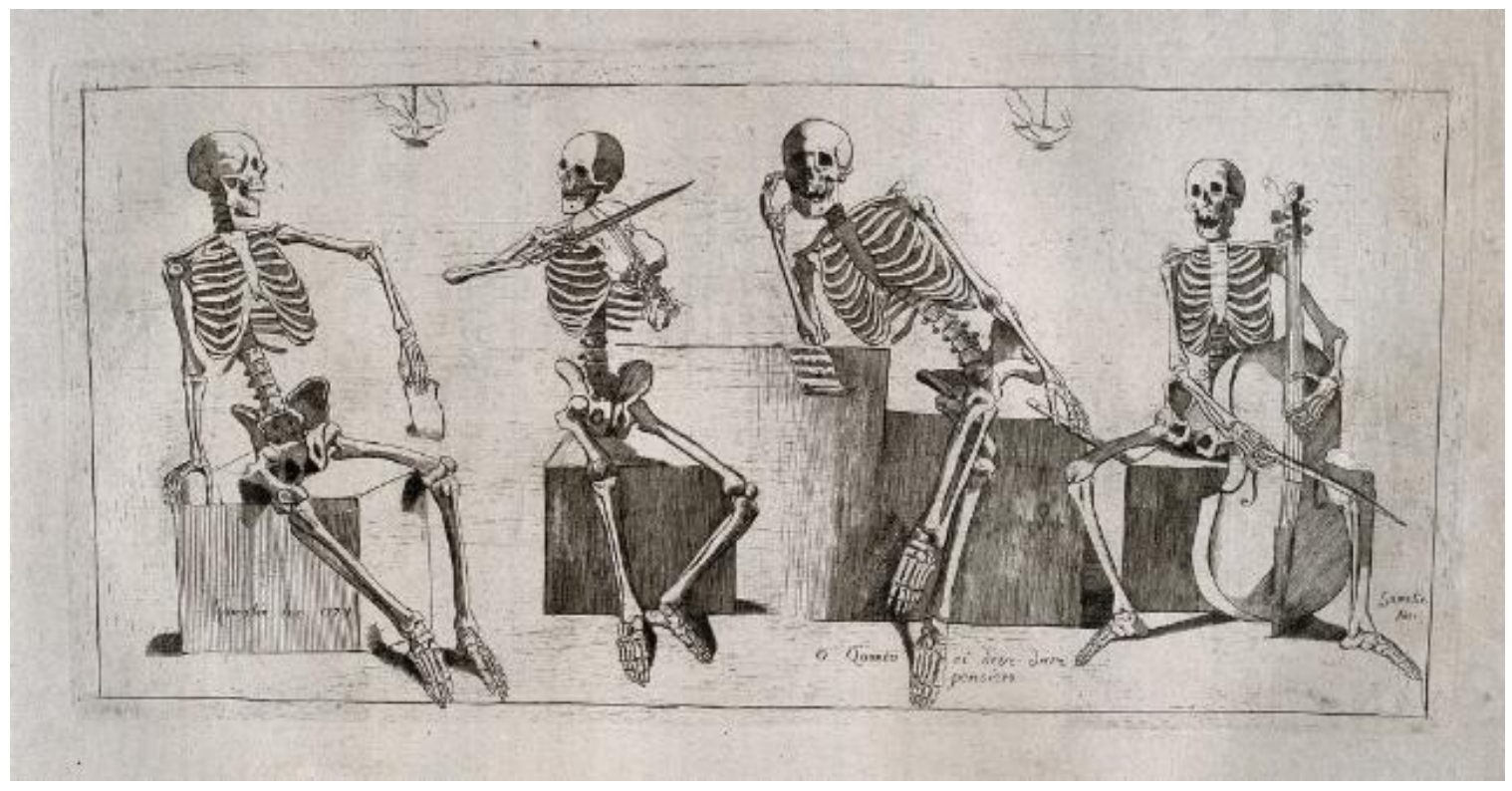

Figure 1. Skeleton in the "musical" closet. The idiom of "skeleton in the closet" is commonly used to describe an undisclosed fact about someone. This image is strength forward what we want to say in opening our article. Four skeletons with musical instruments, seated in various positions: one is singing, another holds a flute, while two others are shown playing the violin and cello. Etching by Lavalée after J. Gamelin, 1778. (This piece can be used for any purpose without restriction under copyright law according to website at: https://wellcomecollection.org/works/f33w7jru). Additional information of copyright is addressed in Public Domain Mark (PDM) terms and conditions https://creativecommons.org/publicdomain/mark/1.0

\section{Bone innervation}

First of all, we believe that sensory innervation is functional and structural important to musician to play an instrument. Immunohistochemistry reveals that the distribution of CGRP-, VIP-, D $\beta \mathrm{H}-$, SP-, and NPY-immunoreactive nerves in whole-mount preparations of periosteum of membranous bones (calvaria, mandible) and long bones (tibia) from the rat(Hill and Elde 1991). The sensory and sympathetic neurotransmitters have trophic effects critically for normal osteogenic differentiation and bone metabolism in bone development and regeneration(Grässel 2014). Similarly, it could modulate bone regeneration, bone remodeling, and articular cartilage homeostasis to their classic neurological actions (Grässel 2014).With touching and hearing mediated osseoperception, sensation can be adapted from the mechanical stimulation of a boneanchored prosthesis (Sci Rep.2017; 7: 45363).

Tomlinson et al demonstrate that "sensory innervation functions in bone much as it does elsewhere in the body - to sense and respond to stimuli, including mechanical loading" (Tomlinson, Christiansen et al. 2020). Sensory innervation of human bone also can be better to 
understand bone pain (Steverink, Oostinga et al. 2021). Bone innervation is livingly dynamic change from development to aging. With aging, the intensity of sensory and sympathetic nerve fibers clearly diminishes (Chartier, Mitchell et al. 2018, Tomlinson, Christiansen et al. 2020). With aging, the sensory and sympathetic nerve fibers significantly declines in the periosteum, while the innervation of cortical bone and bone marrow remain relatively normal(Chartier, Mitchell et al. 2018). Fukuda et al demonstrate that bone-mass is regulated through the sensory innervations (Fukuda, Takeda et al. 2013).

Accordingly, we have a train of thought of osteopenia. Evaluation of the modifications of innervation, a classical in vivo model of osteopenia in rats is examined by ovariectomy (BurtPichat, Lafage-Proust et al. 2005). In this experiment, ovariectomy-induced bone loss is correlated with a reduction in nerve profile density (Burt-Pichat, Lafage-Proust et al. 2005). In neuropathological condition, stump overgrowth is the main sequelae of amputation stumps in children(Abraham, Pellicore et al. 1986). De-innervation can reduce the abnormal overgrowth of bone in rabbit model de-innervation (Garces and Santandreu 1988, Cao, Zhang et al. 2019). Chemical-induced sympathectomy results in reduced osteoblastic activity in the rat femur (Herskovits and Singh 1984). Abnormally, there are high risk factors of heterotopic ossification caused by a sort of de-innervation caused after spinal cord injury(Lal, Hamilton et al. 1989).

Overall, we think that the sensory nerve can precisely let musicians play musical instruments. Intensive practice for musicians will strengthen bone mass or adapt to instrumental condition or specialized mechanical qualification for performance. Regional innervation circuitry will scale to professional level. Bone innervation substantially maintains our body in a physiological health condition.

\section{Music practice involved in bone-mechanical activities: music target bone}

In general, walking, hiking, jogging, climbing stairs, playing tennis, and dancing (Subashi, Butt et al. 2017), such exercises strengthen bones (Milgrom, Finestone et al. 2000, Scholes and Mindell 2016, Tomlinson, Christiansen et al. 2020). While, Music practice involved in similar bonemechanical activities, which enable bone adaptation (Hart, Nimphius et al. 2017). Musical instrumental practice shapes individually kinematic characteristics of muscular-skeleton(Shan and Visentin 2003). Musicians rely on sensation to play instruments. Mechanical loading and mechanical stretch is considered in critical for music performing. NGF-TrkA signaling in skeletal sensory nerves is an early response to mechanical loading of bone (Tomlinson, Li et al. 2017). NGF-TrkA signaling in sensory nerves is required for skeletal adaptation to mechanical loads(Tomlinson, Li et al. 2017). In the CNS, glutamate is an excitatory neurotransmitter in the healthy brain(Zhou and Danbolt 2014). The expression of glutamate transporters on neuronal membranes is associated with reuptake of released neurotransmitters at synapses(Zhou and Danbolt 2014). Mechanical loading regulates the expression of neural glutamate transporter in bones (Mason, Suva et al. 1997). Here we talk about music practice with bone-strengthening activities. Sayilekshmy et al suggest the innervation and vasculature is closely associated in the areas of bone remodeling and the innervation density is higher close to the areas of bone remodeling in human bones by showing a clear anatomical association of nerves to the bone 
remodeling surfaces (Sayilekshmy, Hansen et al. 2019). Interestingly, they demonstrates: "that vasculature and nerves in concert orchestrate the nourishments of local bone remodeling events".

Music practice is acting of mechanical activities based on biological remodeling, meanwhile it is substantially innervation of adaptation. Therefore, for better demonstration of the situation, we figure out a term: from osteo-neruo-plasticity to music-osteo-neuro-plasticity (Figure 2).

\section{Bone innervation to integration of body movement: musculoskeletal-neuromuscular issue}

As we mentioned in the beginning, the finger cortical representative areas can be plastically changed for string players(Elbert, Pantev et al. 1995). From point of view of finger cortical representation (Elbert, Pantev et al. 1995, Larsson, Gulyás et al. 1996, Deiber, Ibanez et al. 1998), we emphasize that bone innervation works as a whole unite together with fingers, arms and shoulders, as well as vision organs, even correlated body together when musician makes music. Beside of cortical representation, we insistent the point of view because of "spinal segmental innervation of bone"(Ivanusic 2007). Anatomically, dermatomes, myotomes and sclerotome corresponding with skin, muscle and skeleton are innervated by single spinal segmental nerves (Murray and McCredie 1979, Hohmann, Elde et al. 1986, Ivanusic 2007, Takahashi, Ohtori et al. 2010).

Musicians play instrument physically to coordinate movement skeleton. For example, pianist play, not just movement of fingers and hands, there are many other coordinating movements(Fraser and Ardan 2003, Mark, Gary et al. 2003). Improperly over exercises causes of physiological injury in piano playing(Fraser and Ardan 2003, Mark, Gary et al. 2003, Niu 2020). The nervous system controls regulate and govern our skeleton and movement system. Bone innervation integrates performer's mind with body movement. We think that the evidence of the bone innervation is that we can feel pain of piano injury, such as 'piano tendonitis' - hand, wrist and elbow injuries as well as piano shoulder etc. Definitely, people start to partially realize that the bones could be involved in these injuries (Ostwald, Baron et al. 1994, Cordell 2009). We can see that people figure out the terms, for example playing-related musculoskeletal disorders(Foxman and Burgel 2006), hand, finger, and wrist musculoskeletal problems in keyboard instrumentalists (Pak and Chesky 2001), musculoskeletal and associated conditions in the instrumental musician (Narducci 2020), musculoskeletal complaints in music students (Baadjou, Verbunt et al. 2015), performance-related upper musculoskeletal injuries(Yang, Fufa et al. 2021), musicians' illness perceptions of musculoskeletal complaints(Kok, Vlieland et al. 2013), musicians' musculoskeletal symptoms(Stanhope, Pisaniello et al. 2020) and common musculoskeletal problems in the performing artist(Hansen and Reed 2006).

Of the injuries encountered many other performing artists, such as string players, ballet dancers, even athletic trainers, we believe that most performance injuries can also be traced back to bone innervation. To prevent these injuries(Ostwald, Baron et al. 1994, Kochevitsky 1995, Cordell 2009), we need to know how the bone innervation affects on our musicians and athletics.

We present these terms because psychological and cognitive acting also have effects on healthy and rewarding life in music and sports in most cases. But over-exercise and inappropriate acting 
cause the unhealthy situation in physical and psychological condition. We will discuss exerciserelated cognitive effects on sensory-motor control and bone innervation in the following section.

\section{Neuropsychological effect on bone homeostasis with musicians and athletics}

Both playing a musical instrument and playing sport produce brain adaptations that might affect sensory-motor functions(Bianco, Berchicci et al. 2017). Neuronal stress might cause disturbing bone homeostasis(Schiavone, Morgese et al. 2016, Camerino, Conte et al. 2018, Huang, Hsu et al. 2018), even tracking to early life stress(Wuertz-Kozak, Roszkowski et al. 2020). Research on the prevention of the neuronal stress hopefully interfere with disturbance of bone homeostasis (Yang, Lu et al. 2017, Lee, Mastronardi et al. 2019, Wippert, Block et al. 2019).

\section{Performing arts medicine}

Performing arts medicine is a relatively new specialty addressing the medical needs of dancers, musicians, ice skaters, and gymnasts (Dommerholt 2009). The sensory nerve of the bone innervation relate to pain, a common symptom of overuse syndrome. Therefore, overuse syndrome, a condition of pain and loss of function in muscle groups and ligaments through excessive use, is common in musicians(Fry 1988).

For musicians, musical instrument practice can cause overuse injury(syndrome) in most cases(Fry 1986, Heming 2004). Bone or muscular-skeleton are vulnerable to injury as usual(Heming 2004, Narducci 2020). However, contrastingly, music therapy as an alternative medicine are used in pain and anxiety management from bone injuries, orthopedic surgery or bone marrow transplantation (Sahler, Hunter et al. 2003, Shabanloei, Golchin et al. 2010, Shabanloei, Golchin et al. 2010, Rosenow and Silverman 2014, Gao, Chen et al. 2016, Ortega, Gauna et al. 2019). A historical review indicates that the best and most reliable treatment for overuse injury (syndrome) is absolute rest for many months(Fry 1986). So, it is reasonable to use the word "adaptation" to demonstrate "bone kinesthetic adaptation of bone innervation plastically developed in fingers and correlated joints of violist and pianist after long term practice".

For personal communication, some of our authors are professional instrument players, music therapist, physical therapist or professional music mentor and music faculty member in music school. We can feel the weakness of our body when we definitely had an overuse problem and suffered pain after tremendous practice. But our musicians still work full of passion for their beloved music because we and many of the musicians think the music is the ego of ourselves. One of our author is a team physical therapist used to serve for the national sport team and knows well how athlete injuries for athletic activities. While the therapist is also a neuroscientist. We figure out the hypothesis about the bone kinesthetic adaptation of bone innervation plastically developed in long-term musical instrument practice.

When musicians experience pain from the overuse syndrome, bone innervation will send a warning message from the sensory nerve. Pain, both acute and chronic, can be categorized into a 
variety of dimensions, which commonly can be nociceptive or neuropathic pain(Nicholson 2006). Actually, the pain of overuse syndrome for musician could be a more complicated sensation. That is why it deals with performing art medicine (Ostwald, Baron et al. 1994, Dommerholt 2009, Bird 2016). The pain tracks to a profound musical psychology. The musician who suffered pain from the overuse syndrome should be addressed and understood with underlying musical behavior and experience.

Sensation of the bone can detect harmful signals for overuse injuries. Prevent further damage of the tissues of muscular-skeleton and correlated joints. If the skeleton sensory nerve dese not work properly, cumulative damages result in severe injuries that could ultimately turn to irreversible disorders if the injured condition was not treated. Sympathetic and parasympathetic nerves can act on metabolism and regeneration to restore and remand normal physiological functioning of the muscular-skeleton that works for musical performance.

We thought that one of the reasons caused overuse syndrome for musicians is that playing music is enjoyable and rewarding activities to excite the sympathetic system. The excitatory effect of sympathetic system can elevate the threshold of pain sensation or inhibit sensory fibers of the pain detecting circuit. Siyu Tian, one of our co-author said that she was suffering a sort of pain before performance with overuse syndrome. But, Siyu Tian may not feel or overlook her pain temporally when started to play the piano. It is not clear the mechanism how the minding of music performance takes over musician's pain when they start to make music. Such, we think that the pain suffered with Siyu Tian is a specialized situation, which many musicians have to face the challenge. In this case, we think that music and or making music itself can function as painreliever (Krout 2001, Rosenow and Silverman 2014). Even in healthy subjects, activation of sympathetic nervous system can partly suppress pain by descending inhibition of nociceptive transmission in the CNS (Schlereth and Birklein 2008). However, pain sensation as a protecting mechanism, chronic pain for example inflammation or nociceptive activation is enhanced to a certain threshold, CNS can initiate protecting mechanism and finally reverse to CNS facilitation(Seifert and Maihöfner 2011). In contrast to cutaneous noxious stimulation, we thought that the deep muscular skeleton pain may show more diverse results. Engagement of music, musician's sensory process work on an established scaling neuronal mechanism which is specialized neuroplasticity on music (Schlaug 2001, Münte, Altenmüller et al. 2002, Gaser and Schlaug 2003). In some experiment of awake human, the sympathetic responses to pain are psychogenic (Burton, Brown et al. 2008). Actually, we are more expecting about more results of pain perception experiments based on innervation of bone and correlated joints. We think that overuse syndrome is involved in intermingled sensory signaling pathways, not currently known as classic or traditional sensory signaling pathway, because of the bone innervation. We emphasize that the peripheral neuronal modalities based on the bone innervation. The CNS could invocate the bone innervation with music practice. The dimension of sensation is scaling to musician's model, bone kinesthetic adaptation based on functional connectivity of bone innervation.

Severe pain sensation definitely send feedback information and may force musician to take rest, which prevent musician from getting in further threatened trouble for the overuse syndromes. Bone innervation of sensory nerve functions as both performing control and warning overuse. As 
we know, the parasympathetic system initiates the rest-and-digest or feed-and-breed responses. So, the bone innervation of parasympathetic nerve responses the rest after intensive or excessive instrument practice and performing. That the bone innervated sensory, sympathetic and parasympathetic nerves are the perfect bio-architecture and built-in auto-control system. As we mentioned above, musicians can even take a rest for months to recover from their overuse syndrome 100 years ago(Fry 1986).

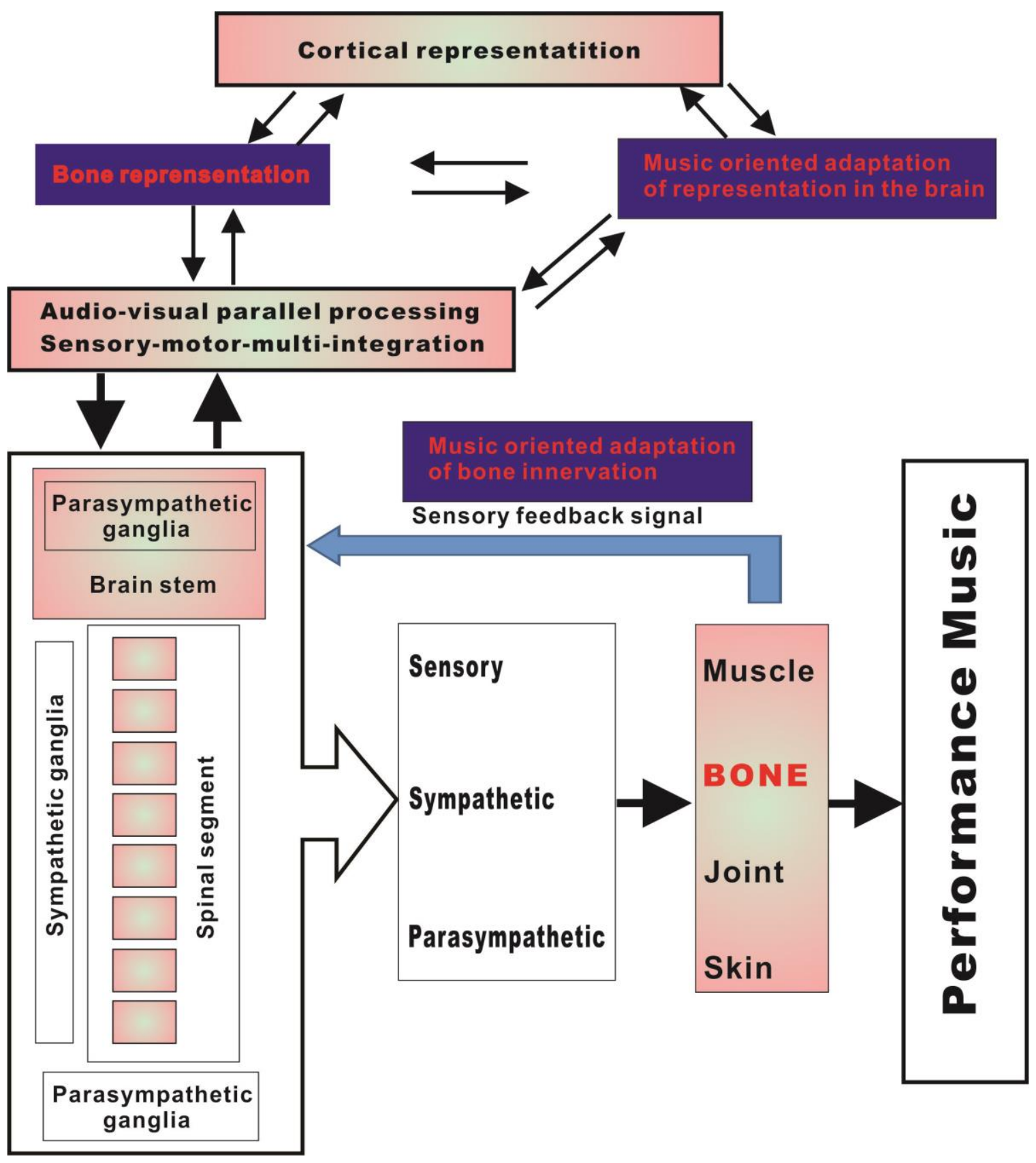

Figure 2. Bone innervation critically completes constitution of music performance. We highlight bone as function organ, which is innervated nerve to accomplish music performance. In 
this illustration, bone innervation can send inputs to CNS and get adaptation through profound music practice. Eventually, performing related fingers representation and its network establish in brain. The finger representation includes bone sensation component.

\section{Conclusion}

The study based on the hypothesis could help to prevent, manage the occupational disorders and explore a new strategy to treatment the disorders. We would like to quote an expectation of Tomlinson el at "more study is required to translate our current knowledge of bone-nerve crosstalk to novel therapeutic strategies that can be effectively utilized to combat skeletal diseases, disorders of low bone mass, and age-related decreases in bone quality"(Tomlinson, Christiansen et al. 2020).

We, human beings, can play music because we have the mechanism of music mind and music playing muscular skeleton as well as correlated joints. Neuronal regulation controls our practice and performance, even in charge of ready to use health body tissues. Bone kinesthetic adaptation of bone and correlated joints innervation could take over part of mechanism muscular-skeleton injury for overuse syndrome in musician and athlete. Music minding produces a profound of neuronal psychology mechanism. It is a specialized motor-sensory integration and processes. At least, we try to interpret the pain of overuse syndrome based on bone innervation and kinesthetic adaptation in this review. Pain sensation due to overuse symptom could underlie a unique mechanism with engagement in music psychology and neuroplasticity.

Conflicts of Interest: The authors declare no conflict of interest.

\section{References}

Abraham, E. H., R. J. Pellicore, R. C. Hamilton, B. W. Hallman and L. Ghosh (1986). "Stump overgrowth in juvenile amputees." Journal of pediatric orthopedics 6 1: 66-71.

Baadjou, V. A., J. A. Verbunt, M. D. van Eijsden-Besseling, S. Huysmans and R. J. Smeets (2015). "The musician as (in) active athlete? Exploring the association between physical activity and musculoskeletal complaints in music students." Medical problems of performing artists 30(4): 231-237.

Bajayo, A., A. Bar, A. Denes, M. Bachar, V. Kram, M. Attar-Namdar, A. Zallone, K. J. Kovács, R. Yirmiya and I. Bab (2012). "Skeletal parasympathetic innervation communicates central IL-1 signals regulating bone mass accrual." Proceedings of the National Academy of Sciences 109(38): 15455-15460.

Bianco, V., M. Berchicci, R. L. Perri, F. Quinzi and F. Di Russo (2017). "Exercise-related cognitive effects on sensory-motor control in athletes and drummers compared to non-athletes and other musicians."

Neuroscience 360: 39-47.

Bird, H. A. (2016). Performing arts medicine in clinical practice, Springer.

Bjurholm, A. (1991). "Neuroendocrine peptides in bone." International orthopaedics 15(4): 325-329.

Burt-Pichat, B., M. H. Lafage-Proust, F. Duboeuf, N. Laroche, C. Itzstein, L. Vico, P. D. Delmas and C. Chenu (2005). "Dramatic Decrease of Innervation Density in Bone after Ovariectomy." Endocrinology 146(1): 503510. 
Burton, A. R., R. Brown and V. G. Macefield (2008). "Selective activation of muscle and skin nociceptors does not trigger exaggerated sympathetic responses in spinal-injured subjects." Spinal Cord 46(10): 660665 .

Byl, N. N., M. M. Merzenich and W. M. Jenkins (1996). "A primate genesis model of focal dystonia and repetitive strain injury." I. Learning-induced dedifferentiation of the representation of the hand in the primary somatosensory cortex in adult monkeys 47(2): 508-520.

Calvo, W. (1968). "The innervation of the bone marrow in laboratory animals." Am J Anat 123(2): 315-328. Camerino, C., E. Conte, R. Caloiero, A. Fonzino, M. Carratù, M. D. Lograno and D. Tricarico (2018).

"Evaluation of short and long term cold stress challenge of nerve grow factor, brain-derived neurotrophic factor, osteocalcin and oxytocin mrna expression in bat, brain, bone and reproductive tissue of male mice using real-time pcr and linear correlation analysis." Frontiers in physiology 8: 1101.

Cao, J., S. Zhang, A. Gupta, Z. Du, D. Lei, L. Wang and X. Wang (2019). "Sensory Nerves Affect Bone

Regeneration in Rabbit Mandibular Distraction Osteogenesis." International journal of medical sciences 16(6): 831-837.

Chartier, S. R., S. A. T. Mitchell, L. A. Majuta and P. W. Mantyh (2018). "The Changing Sensory and Sympathetic Innervation of the Young, Adult and Aging Mouse Femur." Neuroscience 387: 178-190. Cordell, K. N. (2009). "Piano Performance Injuries and Preventions."

Deiber, M.-P., V. Ibanez, M. Honda, N. Sadato, R. Raman and M. Hallett (1998). "Cerebral processes related to visuomotor imagery and generation of simple finger movements studied with positron emission tomography." Neuroimage 7(2): 73-85.

Dommerholt, J. (2009). "Performing arts medicine-instrumentalist musicians Part I-General considerations." Journal of bodywork and movement therapies 13(4): 311-319.

Edoff, K., M. Grenegård and C. Hildebrand (2000). "Retrograde tracing and neuropeptide immunohistochemistry of sensory neurones projecting to the cartilaginous distal femoral epiphysis of young rats." Cell Tissue Res 299(2): 193-200.

Elbert, T., C. Pantev, C. Wienbruch, B. Rockstroh and E. Taub (1995). "Increased Cortical Representation of the Fingers of the Left Hand in String Players." Science 270(5234): 305-307.

Elefteriou, F. (2008). "Regulation of bone remodeling by the central and peripheral nervous system." Archives of Biochemistry and Biophysics 473(2): 231-236.

Foxman, I. and B. J. Burgel (2006). "Musician health and safety: Preventing playing-related musculoskeletal disorders." AAOHN journal 54(7): 309-316.

Fraser, A. and S. Ardan (2003). The craft of piano playing: A new approach to piano technique, Rowman \& Littlefield.

Fry, H. J. (1986). "Overuse syndrome in musicians--100 years ago. An historical review." Med J Aust 145(1112): 620-625.

Fry, H. J. (1986). "Overuse syndrome in musicians: prevention and management." Lancet 2(8509): 728-

731.

Fry, H. J. (1989). "Overuse syndromes in instrumental musicians." Semin Neurol 9(2): 136-145.

Fry, H. J. H. (1986). "How to Treat Overuse Injury: Medicine for Your Practice." Music Educators Journal 72(9): 46-49.

Fry, H. J. H. (1988). "The Treatment of Overuse Syndrome in Musicians. Results in 175 Patients." Journal of the Royal Society of Medicine 81(10): 572-575.

Fukuda, T., S. Takeda, R. Xu, H. Ochi, S. Sunamura, T. Sato, S. Shibata, Y. Yoshida, Z. Gu, A. Kimura, C. Ma, C. Xu, W. Bando, K. Fujita, K. Shinomiya, T. Hirai, Y. Asou, M. Enomoto, H. Okano, A. Okawa and H. Itoh (2013). "Sema3A regulates bone-mass accrual through sensory innervations." Nature 497(7450): 490-493.

Gao, J., S. Chen, S. Lin and H. Han (2016). "Effect of music therapy on pain behaviors in rats with bone cancer pain." J BUON 21(2): 466-472.

Garces, G. L. and M. E. Santandreu (1988). "Longitudinal bone growth after sciatic denervation in rats." The Journal of bone and joint surgery. British volume 70(2): 315-318.

García-Castellano, J. M., P. Díaz-Herrera and J. A. Morcuende (2000). "Is bone a target-tissue for the nervous system? New advances on the understanding of their interactions." The lowa orthopaedic journal 20: 49-58.

Gaser, C. and G. Schlaug (2003). "Brain structures differ between musicians and non-musicians." Journal of 
neuroscience 23(27): 9240-9245.

Grässel, S. (2014). "The role of peripheral nerve fibers and their neurotransmitters in cartilage and bone physiology and pathophysiology." Arthritis research \& therapy 16(6): 1-13.

Hackney, R. G. (1994). "ABC of sports medicine. Nature, prevention, and management of injury in sport." Bmi 308(6940): 1356-1359.

Hansen, P. A. and K. Reed (2006). "Common musculoskeletal problems in the performing artist." Physical Medicine and Rehabilitation Clinics 17(4): 789-801.

Hart, N. H., S. Nimphius, T. Rantalainen, A. Ireland, A. Siafarikas and R. U. Newton (2017). "Mechanical basis of bone strength: influence of bone material, bone structure and muscle action." Journal of musculoskeletal \& neuronal interactions 17(3): 114-139.

Heming, M. (2004). "Occupational injuries suffered by classical musicians through overuse." Clinical Chiropractic 7(2): 55-66.

Herskovits, M. S. and I. J. Singh (1984). "Effect of guanethidine-induced sympathectomy on osteoblastic activity in the rat femur evaluated by 3H-proline autoradiography." Acta Anat (Basel) 120(3): 151-155.

Hill, E. L. and R. Elde (1991). "Distribution of CGRP-, VIP-, D beta H-, SP-, and NPY-immunoreactive nerves in the periosteum of the rat." Cell Tissue Res 264(3): 469-480.

Hill, E. L. and R. Elde (1991). "Distribution of CGRP-, VIP-, DBH-, SP-, and NPY-immunoreactive nerves in the periosteum of the rat." Cell and tissue research 264(3): 469-480.

Hohmann, E. L., R. P. Elde, J. A. Rysavy, S. Einzig and R. L. Gebhard (1986). "Innervation of periosteum and bone by sympathetic vasoactive intestinal peptide-containing nerve fibers." Science 232(4752): 868-871.

Huang, W. S., J. W. Hsu, K. L. Huang, Y. M. Bai, T. P. Su, C. T. Li, W. C. Lin, T. J. Chen, S. J. Tsai and Y. J. Liou (2018). "Post - traumatic stress disorder and risk of osteoporosis: A nationwide longitudinal study." Stress and Health 34(3): 440-445.

Hughes, J. A. E., P. Maiolino and F. lida (2018). "An anthropomorphic soft skeleton hand exploiting conditional models for piano playing." Science Robotics 3(25): eaau3098.

Ivanusic, J. J. (2007). "The evidence for the spinal segmental innervation of bone." Clinical Anatomy 20(8): 956-960.

Ivanusic, J. J. (2007). "The evidence for the spinal segmental innervation of bone." Clin Anat 20(8): 956960.

Kimoto, Y., M. Hirano and S. Furuya (2021). "Adaptation of the Corticomuscular and Biomechanical Systems of Pianists." Cerebral Cortex.

Kochevitsky, G. (1995). The art of piano playing: A scientific approach, Alfred Music.

Kok, L. M., T. P. V. Vlieland, M. Fiocco, A. A. Kaptein and R. G. Nelissen (2013). "Musicians' illness

perceptions of musculoskeletal complaints." Clinical rheumatology 32(4): 487-492.

Krout, R. E. (2001). "The effects of single-session music therapy interventions on the observed and selfreported levels of pain control, physical comfort, and relaxation of hospice patients." American Journal of Hospice and Palliative Medicine ${ }^{\circledR}$ 18(6): 383-390.

Lal, S., B. B. Hamilton, A. Heinemann and H. B. Betts (1989). "Risk factors for heterotopic ossification in spinal cord injury." Archives of physical medicine and rehabilitation 70(5): 387-390.

Larsson, J., B. Gulyás and P. E. Roland (1996). "Cortical representation of self-paced finger movement." Neuroreport 7(2): 463-468.

Lee, S., C. Mastronardi, R. Li, G. Paz-Filho, E. Dutcher, M. Lewis, A. Vincent, P. Smith, S. Bornstein and J. Licinio (2019). "Short-term antidepressant treatment has long-lasting effects, and reverses stress-induced decreases in bone features in rats." Translational psychiatry 9(1): 1-12.

Lockwood, A. H. (1989). "Medical Problems of Musicians." New England Journal of Medicine 320(4): 221227.

Mark, T. C., R. Gary and T. Miles (2003). What every pianist needs to know about the body: A manual for players of keyboard instruments: piano, organ, digital keyboard, harpsichord, clavichord, GIA Publications. Mason, D. J., L. J. Suva, P. G. Genever, A. J. Patton, S. Steuckle, R. A. Hillam and T. M. Skerry (1997).

"Mechanically regulated expression of a neural glutamate transporter in bone: a role for excitatory amino acids as osteotropic agents?" Bone 20(3): 199-205.

Milgrom, C., A. Finestone, A. Simkin, I. Ekenman, S. Mendelson, M. Millgram, M. Nyska, E. Larsson and D. Burr (2000). "In vivo strain measurements to evaluate the strengthening potential of exercises on the tibial 
bone." The Journal of bone and joint surgery. British volume 82(4): 591-594.

Milovanovic, P. and M. ! uri (2018). "Innervation of bones: Why it should not be neglected?" Medicinski Podmladak 69: 25-32.

Mizrahi, J. (2020). "Neuro-mechanical aspects of playing-related mobility disorders in orchestra violinists and upper strings players: a review." European journal of translational myology 30(3): 9095-9095.

Münte, T. F., E. Altenmüller and L. Jäncke (2002). "The musician's brain as a model of neuroplasticity." Nature Reviews Neuroscience 3(6): 473-478.

Murray, R. and J. McCredie (1979). "Melorheostosis and the sclerotomes: a radiological correlation." Skeletal radiology 4(2): 57-71.

Narducci, D. M. (2020). Musculoskeletal and Associated Conditions in the Instrumental Musician. Perspectives in Performing Arts Medicine Practice, Springer, Cham: 197-239.

Nicholson, B. (2006). "Differential diagnosis: nociceptive and neuropathic pain." Am J Manag Care 12(9 Suppl): S256-262.

Niu, R. (2020). Types and Causes of Physiological Injury in Piano Playing, with Emphasis on Piano Pedagogy in China, West Virginia University.

Ortega, A., F. Gauna, D. Munoz, G. Oberreuter, H. A. Breinbauer and L. Carrasco (2019). "Music Therapy for Pain and Anxiety Management in Nasal Bone Fracture Reduction: Randomized Controlled Clinical Trial." Otolaryngol Head Neck Surg 161(4): 613-619.

Ostwald, P. F., B. C. Baron, N. M. Byl and F. R. Wilson (1994). "Performing arts medicine." Western journal of medicine 160(1): 48.

Pak, C. H. and K. Chesky (2001). "Prevalence of hand, finger, and wrist musculoskeletal problems in keyboard instrumentalists: the University of North Texas musician health survey." Medical Problems of Performing Artists 16(1): 17-23.

Rosenow, S. C. and M. J. Silverman (2014). "Effects of single session music therapy on hospitalized patients recovering from a bone marrow transplant: Two studies." The Arts in Psychotherapy 41(1): 65-70.

Sahler, O. J. Z., B. C. Hunter and J. L. Liesveld (2003). "The effect of using music therapy with relaxation imagery in the management of patients undergoing bone marrow transplantation: a pilot feasibility study." Alternative therapies in health and medicine 9(6): 70.

Sayilekshmy, M., R. B. Hansen, J.-M. Delaissé, L. Rolighed, T. L. Andersen and A.-M. Heegaard (2019). "Innervation is higher above Bone Remodeling Surfaces and in Cortical Pores in Human Bone: Lessons from patients with primary hyperparathyroidism." Scientific reports 9(1): 5361-5361.

Schiavone, S., M. G. Morgese, E. Mhillaj, M. Bove, A. De Giorgi, F. P. Cantatore, C. Camerino, P. Tucci, N. Maffulli and V. Cuomo (2016). "Chronic psychosocial stress impairs bone homeostasis: a study in the social isolation reared rat." Frontiers in pharmacology 7: 152.

Schlaug, G. (2001). "The brain of musicians: A model for functional and structural adaptation." Annals of the New York Academy of Sciences 930(1): 281-299.

Schlereth, T. and F. Birklein (2008). "The sympathetic nervous system and pain." Neuromolecular Med 10(3): 141-147.

Scholes, S. and J. Mindell (2016). "Health survey for England 2015 physical activity in children." Leeds: NHS Digital.

Seifert, F. and C. Maihöfner (2011). "Functional and structural imaging of pain-induced neuroplasticity." Current Opinion in Anesthesiology 24(5): 515-523.

Shabanloei, R., M. Golchin, A. Esfahani, R. Dolatkhah and M. Rasoulian (2010). "Effects of music therapy on pain and anxiety in patients undergoing bone marrow biopsy and aspiration." Aorn $j$ 91(6): 746-751. Shabanloei, R., M. Golchin, A. Esfahani, R. Dolatkhah and M. Rasoulian (2010). "Effects of music therapy on pain and anxiety in patients undergoing bone marrow biopsy and aspiration." AORN journal 91(6): 746751.

Shan, G. and P. Visentin (2003). "A quantitative three-dimensional analysis of arm kinematics in violin performance." Medical problems of performing artists 18(1): 3-10.

Sheon, R. P. (1997). "Repetitive strain injury. 2. Diagnostic and treatment tips on six common problems. The Goff Group." Postgrad Med 102(4): 72-78, 81, 85 passim.

Stanhope, J., D. Pisaniello and P. Weinstein (2020). "The effect of strategies to prevent and manage musicians' musculoskeletal symptoms: A systematic review." Archives of Environmental \& Occupational 
Health: 1-21.

Steverink, J. G., D. Oostinga, F. R. van Tol, M. H. P. van Rijen, C. Mackaaij, S. A. M. W. Verlinde-Schellekens, B. J. Oosterman, A. J. M. Van Wijck, T. A. P. Roeling and J.-J. Verlaan (2021). "Sensory Innervation of Human Bone: An Immunohistochemical Study to Further Understand Bone Pain." The Journal of Pain.

Subashi, B., D. S. Butt, F. Kamberi, G. Sinanaj and Y. Bilushi (2017). "Physical activity recommended for osteoporosis prevention." Durreesamin Journal (ISSN: 2204-9827), November 3(3).

Takahashi, Y., S. Ohtori and K. Takahashi (2010). "Sclerotomes in the thoracic and lumbar spine, pelvis, and hindlimb bones of rats." The Journal of Pain 11(7): 652-662.

Tomlinson, R. E., B. A. Christiansen, A. A. Giannone and D. C. Genetos (2020). "The Role of Nerves in Skeletal Development, Adaptation, and Aging." Frontiers in endocrinology 11: 646-646.

Tomlinson, R. E., B. A. Christiansen, A. A. Giannone and D. C. Genetos (2020). "The Role of Nerves in Skeletal Development, Adaptation, and Aging." Frontiers in Endocrinology 11(646).

Tomlinson, R. E., Z. Li, Z. Li, L. Minichiello, R. C. Riddle, A. Venkatesan and T. L. Clemens (2017). "NGF-TrkA

signaling in sensory nerves is required for skeletal adaptation to mechanical loads in mice." Proceedings of the National Academy of Sciences 114(18): E3632-E3641.

Wippert, P.-M., A. Block, I. M. Mansuy, E. M. Peters, M. Rose, M. A. Rapp, A. Huppertz and K. Wuertz-Kozak (2019). "Alterations in bone homeostasis and microstructure related to depression and allostatic load."

Psychotherapy and psychosomatics 88(6): 383-385.

Wuertz-Kozak, K., M. Roszkowski, E. Cambria, A. Block, G. A. Kuhn, T. Abele, W. Hitzl, D. Drießlein, R. Müller and M. A. Rapp (2020). "Effects of early life stress on bone homeostasis in mice and humans."

International journal of molecular sciences 21(18): 6634.

Yang, M., B.-J. Lu, Y.-Y. Duan, X.-F. Chen, J.-G. Ma and Y. Guo (2017). "Genetics association study and functional analysis on osteoporosis susceptibility gene BDNF." Yi Chuan= Hereditas 39(8): 726-736.

Yang, N., D. Fufa and A. Wolff (2021). "A Musician-Centered Approach to Management of Performancerelated Upper Musculoskeletal Injuries." Journal of Hand Therapy.

Zaza, C. (1998). "Playing-related musculoskeletal disorders in musicians: a systematic review of incidence and prevalence." Cmaj 158(8): 1019-1025.

Zhou, Y. and N. C. Danbolt (2014). "Glutamate as a neurotransmitter in the healthy brain." Journal of neural transmission (Vienna, Austria : 1996) 121(8): 799-817. 